( 2022 , The Authors. Published by Elsevier Inc. and Fass Inc. on behalf of the American Dairy Science Association ${ }^{\circledR}$. This is an open access article under the CC BY license (http://creativecommons.org/licenses/by/4.0/).

\title{
Effective and repeatable chromatographic separation of 5 nucleotides in infant formula milk powder by ion-pair high-performance liquid chromatography-ultraviolet
}

\author{
Yuanjia Chen, ${ }^{1}$ Lin Luo, ${ }^{1}$ Peiyan Feng, ${ }^{1}$ Baojun $\mathrm{Xu},{ }^{2 *}$ and Xiaoqun Wei ${ }^{1 *}$ \\ ${ }^{1}$ Guangdong Provincial Key Laboratory of Food Quality and Safety/Guangdong Laboratory of Lingnan Modern Agriculture, \\ South China Agricultural University, Guangzhou, 510642, China \\ ${ }^{2}$ Food Science and Technology Program, BNU-HKBU United International College, Zhuhai, Guangdong 519087, China
}

\begin{abstract}
A robust method using HPLC-UV was developed to improve the accuracy and repeatability of a quantitative method to detect 5 nucleotides (cytidine-monophosphate, uridine monophosphate, adenosine monophosphate, guanine monophosphate, and inosine monophosphate) in infant formulas. The results showed that efficient separation could not be achieved without strict conditions. The proposed method displayed a strong linear relationship $\left(\mathrm{R}^{2}>0.9999\right)$ of single nucleotide in infant formula milk powder in the range of 10 to 1,000 $\mathrm{mg} / \mathrm{kg}$, a steady recovery $(80.0 \% \sim 110.0 \%)$ with relative standard deviation from $0.5 \%$ to $3.5 \%$, under strict conditions of hydrophilic $\mathrm{C}_{18}$ column with di-isopropyl at $62.5 \pm 2.5^{\circ} \mathrm{C}$ ( \pm standard deviation $), 0.65 \pm 0.1 \mathrm{mg} /$ $\mathrm{mL}$ tetrabutylammonium bisulfate, and mobile phase of $\mathrm{pH}$ of $2.75 \pm 0.02$. By applying this method on a series of milk products in the Chinese market, we found a few of them exceeded the legal limits of nucleotides. Key words: nucleotide, infant formula, chromatographic conditions, high-performance liquid chromatographyultraviolet
\end{abstract}

\section{INTRODUCTION}

Nucleotides are crucial to the growth of infants (Garwolińska et al., 2018). They have numerous biological effects such as improving the intestinal flora (Doo et al., 2017; Wang et al., 2019) and the immunity function (Gil, 2002; Singhal et al., 2010), modulating the lipid metabolism (Siahanidou et al., 2004), and promoting better sleep (Sánchez et al., 2009). Nucleotides are often added during the production of infant formula because cow milk contains less nucleotides than human

Received August 9, 2021.

Accepted December 27, 2021.

*Corresponding author: weixqun@scau.edu.cn breast milk (Zhang et al., 2014). However, Codex Alimentarius (2020) advocated that the total nucleotide level needs to be determined by national authorities, as consuming more nucleotides might be potentially harmful, including an increased risk of respiratory infections (Yau et al., 2003). Countries around the world, such as the European Union (2016), Australia and New Zealand (Food Standards Australian and New Zealand, 2019), and China (Ministry of Health of the People's Republic of China, 2012), have imposed regulations on nucleotide contents in infant formula products. The commonly added nucleotides are cytidine 5'-monophosphate [CMP; 4-imino-1-(5-O-phosphono$\beta$-D-ribofuranosyl)-1,4-dihydro-2-pyrimidinol], uridine monophosphate [UMP; 4-hydroxy-1-(5-O-phosphono$\beta$-D-ribofuranosyl)-2(1H)-pyrimidinone], AMP (5'-adenylic acid), guanine monophosphate [GMP; 2-imino-9-(5-O-phosphono- $\beta$-D-ribofuranosyl)-3,9-dihydro$2 \mathrm{H}$-purin-6-ol], and inosine monophosphate (IMP; 5 '-inosinic acid). To establish a good market order and ensure the healthy growth of infants, it is important to monitor the quantity of nucleotides in infant formula products. This requires the corresponding technical support.

Many methods have been reported to detect the 5 nucleotides in milk powder so far. There have been attempts to use both the $\mathrm{C}_{18}$ chromatographic columns (widely used to separate nonpolar compounds; Gill and Indyk, 2007; Chen et al., 2021) and the amide chromatographic columns (commonly used to separate sugars; Mateos-Vivas et al., 2016; Ma et al., 2019) with HPLC to determine nucleotides. However, the lactose, which is more than $50 \%$ of the milk powder matrix, often flows out together with 1 or more of the 5 nucleotides (Chen et al., 2020) due to the similar structures. Hence, complex pretreatments, such as solid phase extraction (Ma et al., 2019), precipitated impurities (Viñas et al., 2010), or isotope internal standard method (Inoue et al., 2010; Gill et al., 2013) have generally been required in these methods. 
To simplify the pretreatment and avoid expensive reagents, we focused on the ion-pair reagent method based on $\mathrm{C}_{18}$ columns by HPLC-UV. The phosphoric acid in 5 nucleotides combined with the ion-pair reagent to extend their retentions in $\mathrm{C}_{18}$ chromatographic columns and to differentiate from lactose (Yang et al., 2010; Mateos-Vivas et al., 2015, 2016). Moreover, the UV detection incurs a low cost and will not be polluted by the ion-pair reagent. However, it is still a challenge to detect the 5 nucleotides in milk powder by HPLCUV with $\mathrm{C}_{18}$ chromatographic columns simultaneously. For one challenge, the accuracy of the methods is insufficient. This is because the binding force between the 5 nucleotides and the ion-pair reagent belongs to a nonchemical bond, and the interaction between the nucleotides and the column is greatly affected by the analysis conditions. Slight changes in the column packing (Cohen et al., 2010; Zhu et al., 2018), the $\mathrm{pH}$ value of the mobile phase (Studzińska and Buszewski, 2013), the concentration of the ion-pair reagent (Gil et al., 2007), or the column temperature will affect the separation effect (Johnsen et al., 2011). Another challenge is that the repeatability of the methods will be compromised due to the rapid loss of the column efficiency in conventional $\mathrm{C}_{18}$ chromatographic columns with ionpair reagents (Chen et al., 2021), which is an important but easy to ignore problem. Therefore, improving the repeatability and accuracy of the determination of 5 nucleotides in infant formula based on a $\mathrm{C}_{18}$ column with ion-pair reagents by HPLC-UV remains an urgent problem.

Considering this context, to quantify nucleotides more effectively and to explain their mechanisms, we investigated the retention time of the 5 nucleotides under more precise $\mathrm{pH}$ values $( \pm 0.01)$, a greater range of column temperatures, and a broader range of ion-pairing reagent concentrations. These findings are expected to have a wide range of applications that involve the separation, preparation, and quantification of nucleotides.

\section{MATERIALS AND METHODS}

\section{Chemicals and Reagents}

We purchased the CMP, UMP, AMP, GMP, and IMP (standard, purity of $99 \%$ or more) from Sigma. Tetrabutylammonium bisulfate (THS; purity of 98\%), a reagent used in the mobile phase, was purchased from Aladdin. Acetonitrile, methanol, and phosphoric acid, were of HPLC grade (Thermo Fisher Scientific). Purified water was obtained from a Milli-Q Advantage A10 water purification system (Merck). Commercial sam- ples of infant formula were collected from the domestic market, and the imported samples were collected from the Guangzhou Customs.

\section{Preparation of Standards}

Standard solution $(1.0 \mathrm{mg} / \mathrm{mL})$ of each nucleotide was prepared by dissolving $25 \mathrm{mg}$ (accurate to $0.001 \mathrm{~g}$ ) of standard in water and diluting it with water to 25 $\mathrm{mL}$. Intermediate solution was used to prepare mixture of $1 \mathrm{~mL}$ of $1.0 \mathrm{mg} / \mathrm{mL} \mathrm{CMP} \mathrm{standard} \mathrm{solution,} 1 \mathrm{~mL}$ of $1.0 \mathrm{mg} / \mathrm{mL}$ UMP standard solution, $1 \mathrm{~mL}$ of $1.0 \mathrm{mg} /$ $\mathrm{mL}$ AMP standard solution, $1 \mathrm{~mL}$ of $1.0 \mathrm{mg} / \mathrm{mL}$ GMP standard solution, $1 \mathrm{~mL}$ of $1.0 \mathrm{mg} / \mathrm{mL}$ IMP standard solution, and $15 \mathrm{~mL}$ of water at concentration $50 \mu \mathrm{g} /$ $\mathrm{mL}$. The mixed standard solutions were diluted with water to the required concentrations $(50 \mu \mathrm{g} / \mathrm{mL}, 25$ $\mu \mathrm{g} / \mathrm{mL}, 10 \mu \mathrm{g} / \mathrm{mL}, 5 \mu \mathrm{g} / \mathrm{mL}, 2 \mu \mathrm{g} / \mathrm{mL}, 1 \mu \mathrm{g} / \mathrm{mL}$, and $0.5 \mu \mathrm{g} / \mathrm{mL}$ ) as standard working solutions. These stock solutions (valid for $3 \mathrm{mo}$ ) were stored in brown glass bottles at $4^{\circ} \mathrm{C}$.

\section{Preparation of Samples}

An aliquot of $0.5 \mathrm{~g}$ of sample was put into a $50-\mathrm{mL}$ centrifuge tube and mixed with $10 \mathrm{~mL}$ of water. The glacial acetic acid adjusted $\mathrm{pH}$ to 4 to 5 to precipitate the protein. Then, the tube was vortexed for $5 \mathrm{~min}$, followed by centrifugation at 10,397 $\times g$ for $10 \mathrm{~min}$ at $20^{\circ} \mathrm{C}$. The supernatant was transferred into the specimen bottle and then diluted with water to $10 \mathrm{~mL}$. The diluted supernatant $(1 \mathrm{~mL})$ was filtered through 0.25 $\mu \mathrm{m}$ membrane filters and kept for $60 \mathrm{~h}$ to allow for HPLC analysis.

\section{HPLC-UV Analysis}

All separation was performed on a 30A HPLC system equipped with a photo-diode array. An Agilent ZORBAX SB-AQ column $(3 \mu \mathrm{m}, 4.6 \mathrm{~mm} \times 150 \mathrm{~mm})$ was used at $65^{\circ} \mathrm{C}$. The injection volume was $10 \mu \mathrm{L}$. The detection wavelength was set at $254 \mathrm{~nm}$. The mobile phase consisting of solvent A $(0.6 \mathrm{mg} / \mathrm{mL}$ THS $)$ solution ( $\mathrm{pH} 2.75$, adjusted by $2 \mathrm{~mol} / \mathrm{L}$ disodium hydrogen phosphate solution or phosphoric acid) and solvent B (acetonitrile) was used to deliver compounds in samples at a flow rate of $1.0 \mathrm{~mL} / \mathrm{min}$. The stepwise elution was as follows: 0 to $12 \mathrm{~min}, 0 \% \mathrm{~B} ; 12$ to $15 \mathrm{~min}, 0$ to $100 \%$ B; 15 to $20 \mathrm{~min}, 100 \% \mathrm{~B} ; 20$ to $25 \mathrm{~min}, 0 \% \mathrm{~B}$. This method was optimized based on published national standards (Ministry of Health of the People's Republic of China, 2012). 


\section{Method Validation}

To validate a sensitive and reliable HPLC method for the quantification of nucleotides in milk powder, the studies on linearity, sensitivity, specificity, and precision were carried out. The linearity of the calibration curves was made by plotting 7 different concentrations $(0.5$, $2.0,5.0,10.0,20.0,25.0$, and $50.0 \mu \mathrm{g} / \mathrm{mL}$ ) and their peak area over the defined range of calibration. The limit of detection (LOD) and the limit of quantification (LOQ) were detected when the signal-to-noise ratio was 3 and 10 times of the chromatographic response, respectively. The calculation equations were listed in the following Eq. 1 and 2:

$$
\begin{gathered}
\mathrm{LOD}=3 \times \mathrm{SD}_{(\mathrm{b})} / \mathrm{a}, \\
\mathrm{LOQ}=10 \times \mathrm{SD}_{(\mathrm{b})} / \mathrm{a},
\end{gathered}
$$

where $\mathrm{SD}_{(\mathrm{b})}$ is the standard deviation of the intercept and $\mathrm{a}$ is the slope of the calibration curve.

To assess matrix effects, the specificity was investigated through the spike-and-recovery experiments. Preparation and detection of the spiked samples were in accordance with optimized pretreatment and chromatographic conditions. We analyzed the peak areas of the standards spiked in sample matrix and determined the standard solvent to obtain the relative recovery rates, which could be calculated according to Eq. 3. Each concentration level was determined 6 times. The equation is as follows:

$$
\text { Recovery }(\%)=\left[\left(\mathrm{C}_{1}-\mathrm{C}_{2}\right) / \mathrm{C}_{3}\right] \times 10,
$$

where $\mathrm{C}_{1}$ is the concentration determined in spiked sample, $\mathrm{C}_{2}$ is the concentration determined in unspiked sample, and $\mathrm{C}_{3}$ is the concentration of spiked analyte.

\section{Statistical Analysis}

The recovery tests were repeated 6 times to get the mean and calculate their relative standard variance. Other determinations were carried out in triplicates, and the resulting data were expressed as mean \pm standard deviation. The significant differences between the means of different samples were calculated by one-way ANOVA. Duncan test was used to determine whether there were significant differences $(P<0.05)$ among the values. All data were analyzed in SPSS software (version 22, IBM Co.). The linear curves were obtained by fitting 6 data points in Origin software (version 8.6, Origin Lab Co.).

\section{RESULTS AND DISCUSSION}

\section{Method Development}

Effect of Column Temperature on Nucleotide Retention Time. It was found that the ratio of water phase required for an ideal separation effect was $100 \%$ during the preliminary experiment. The Agilent ZORBAX SB-AQ column, a kind of hydrophilic $\mathrm{C}_{18}$ chromatographic column bounded with di-isopropyl, was chosen for experiments. This column performance was still good in the presence of the ion pair because di-isopropyl side chain groups form steric hindrance to prevent the water phase from coming in contact with the silica gel. Generally, the separation effect of the compound is better with lower column temperatures. However, we found that the low temperature could not separate the nucleotides well through the experiment. Therefore, the effect of temperature on retention time was investigated by varying the column temperature from 35 to $80^{\circ} \mathrm{C}$ (10 calibrations) when the concentration of ion-pair reagent was $10 \mathrm{mmol} / \mathrm{L}$ and the $\mathrm{pH}$ was 2.75. As shown in Figure 1a, the retention time generally decreased with higher temperature, except for CMP. In addition, there was no overlap among the retention time curves of CMP, GMP, IMP, and UMP. However, the AMP curve intersected with that of GMP and IMP curves at 35 to $55^{\circ} \mathrm{C}$ and 70 to $80^{\circ} \mathrm{C}$, respectively. Therefore, it was evident that the optimal column temperature was between 60 and $65^{\circ} \mathrm{C}$ at the established ion-pair reagent concentration and $\mathrm{pH}$.

Higher temperatures could reduce the polarity of mobile phase (Johnsen, et al., 2011) and shorten retention time of 5 nucleotides. It was required to find out whether the AMP had larger polarity changes than other nucleotides when heating in other nonpolar chromatographic columns. As shown at Figure 1b, the $\mathrm{NH}_{2}$ linked to the plane-structure C (4) changed from the $\mathrm{p}-\pi$ conjugate structure to the noncoplanar structure and caused the AMP to become less polar and remain longer when heating. Although other nucleotides had O as the fourth carbon of their nitrogenous base, it can be inferred from the results that the structures were more thermally stable.

Effect of Mobile Phase PH on Nucleotide Retention Time. As for the $\mathrm{pH}$ value, a wide range (or accurate to one decimal point) was permitted in most reports (Gill et al., 2013), which was not strict enough. We took the recommended range into the experiment but found it did not always work; therefore, a more precise $\mathrm{pH}$ value needed to be determined by controlling other factors as invariant. When the concentration of ion-pair reagent was $10 \mathrm{mmol} / \mathrm{L}$ and the column 
(a)
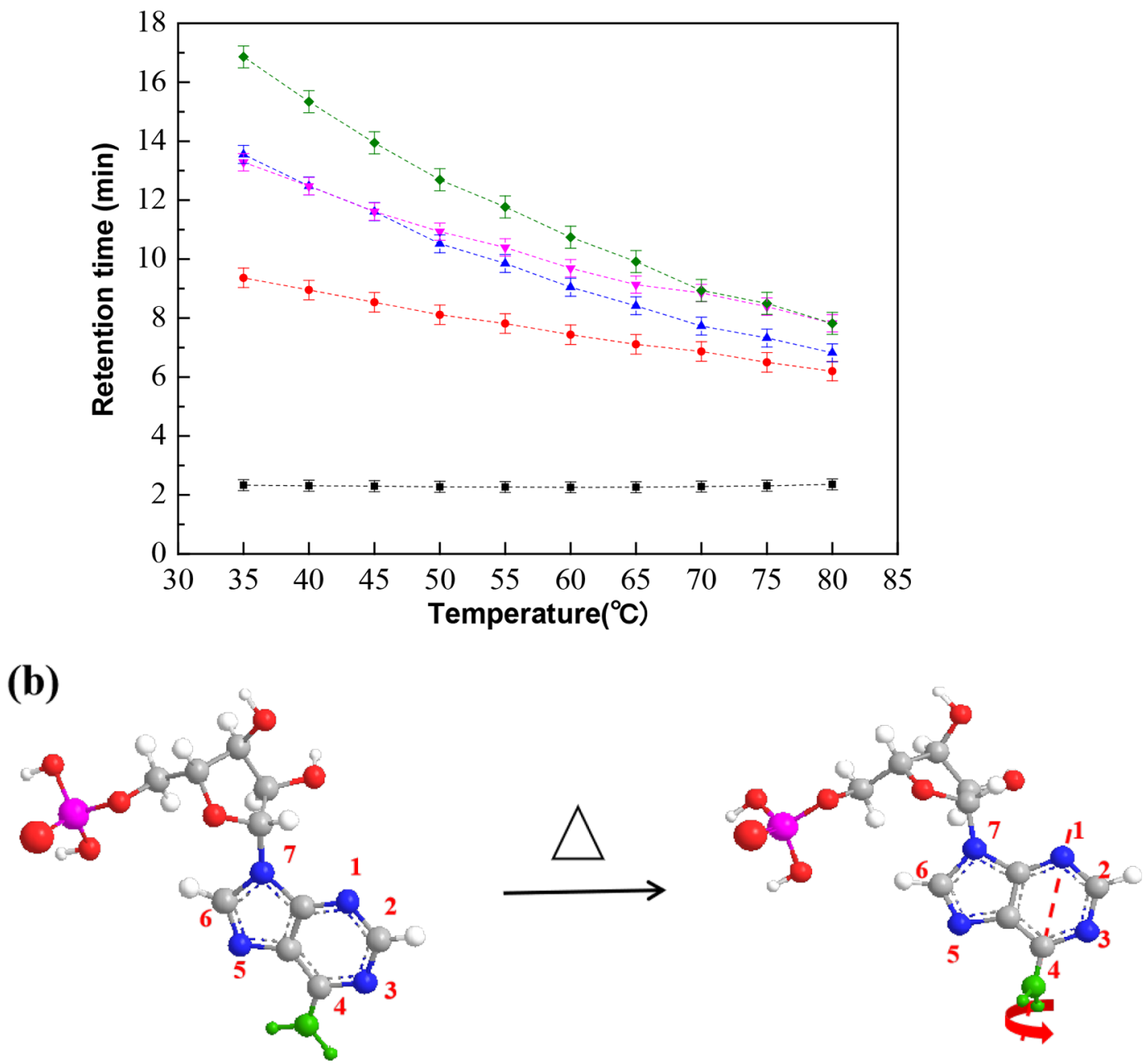

AMP

Figure 1. Effects of HPLC column temperature on (a) retention time of 5 nucleotides, and (b) the potential change of chemical structure of AMP. The range of retention time at different temperatures represent the width of the nucleotides' chromatographic peaks. Symbols are represented as follows: $(\mathbf{\square})$ cytidine $5^{\prime}$-monophosphate, $(\bullet)$ uridine monophosphate, $(\boldsymbol{\Lambda})$ guanine monophosphate, $(\mathbf{\nabla})$ AMP, and $(\bullet)$ inosine monophosphate. The numbers on the rings are arranged according to the International Union of Pure and Applied Chemistry (IUPAC) nomenclature.

temperature was $60^{\circ} \mathrm{C}$, the recommended range of $\mathrm{pH}$ values from 2.65 to 3.10 (14 calibrations) was performed in a comparative study of analytic separation.

We observed that the $\mathrm{pH}$ value had little effect on retention time of CMP, UMP, IMP, and GMP, and their separation did not interfere with each other (Figure 2a). However, AMP was sensitive to the $\mathrm{pH}$ value, and its retention time curve intersected the GMP and IMP curves between pH 2.65 to 2.90. Based on this result, a good separation of investigated nucleotides can be obtained with the $\mathrm{pH}$ value at $2.75 \pm 0.02$ or between 2.90 and 3.10. In addition, based on IMP and GMP retention time curves, it could be inferred that these 2 may intersect when the $\mathrm{pH}$ value is greater than 3.10 . Therefore, the optimized $\mathrm{pH}$ results range from 2.75 \pm 0.02 and 2.90 to 3.10 , where the first range requires more precise control to achieve a good separation result.

Inspectors have changed the $\mathrm{pH}$ of the mobile phase for optimizing the shape of chromatographic peaks and prolonging the retention time of target compounds (Buszewski and Noga, 2012). Inspectors would be interested to discover the correlation between hydrogen icon concentration of mobile phase and the peak sequence in $\mathrm{C}_{18}$ chromatographic column. A tautomeric structure model of AMP effected by $\mathrm{H}^{+}$was thus proposed. As shown in Figure 2b, the atom N (5) in the nitrogenous base would have charges in the mobile phase with a higher concentration of $\mathrm{H}^{+}$, which destroyed the conjugated $\pi$ bonds on 5-membered ring and enhanced the polarity of AMP. Hence, the retention time of AMP 
was largely shortened, whereas retention times of other nucleotides remained the same. The AMP could be separated from other nucleotides and impurities in $\mathrm{C}_{18}$ columns by adjusting the $\mathrm{pH}$ to control the retention time.

Effect of Ion-Pair Reagent Concentration on Retention Time of Nucleotides. In preliminary experiments, we discovered that the retention of nucleotides in the chromatographic column was very weak without ion-pair reagents in the mobile phase, and all nucleotides flowed out within $2 \mathrm{~min}$. Therefore, the ionpair reagent THS was added to increase the bond force (Seifar et al., 2009), and the effect of THS was investigated by varying the concentration between 0.25 and $1.00 \mathrm{mg} / \mathrm{mL}$. Similar to the effect of the $\mathrm{pH}$ value, the AMP interfered with the retention of GMP and IMP when the ion-pair reagent concentration was between
0.25 and $1.00 \mathrm{mg} / \mathrm{mL}$ (5 calibrations) at $65^{\circ} \mathrm{C}$ column temperature and $2.75 \mathrm{pH}$ (Figure 3a). Judging from their retention time curves, the optimum concentration of THS for separation was 0.55 to $0.75 \mathrm{mg} / \mathrm{mL}$.

It has been reported that the retention times of compounds with different structures were affected differently by changing the concentration of the ion pair (Qiao et al., 2018). This study found 4 nucleotides, each with a hydroxyl group of the bicyclic conjugate structure, had shorter retention times by increasing the ion-pair reagent concentration in the mobile phase, whereas the time of AMP remained the same. It should note that the enol group could transfer into a ketone group in the keto-enol tautomerism (Sheina et al., 1985). For example, when the tetrabutylammonium salt concentration increased in IMP (Figure 3b), the H atom of the hydroxyl group bonded to its adjacent ni-

(a)
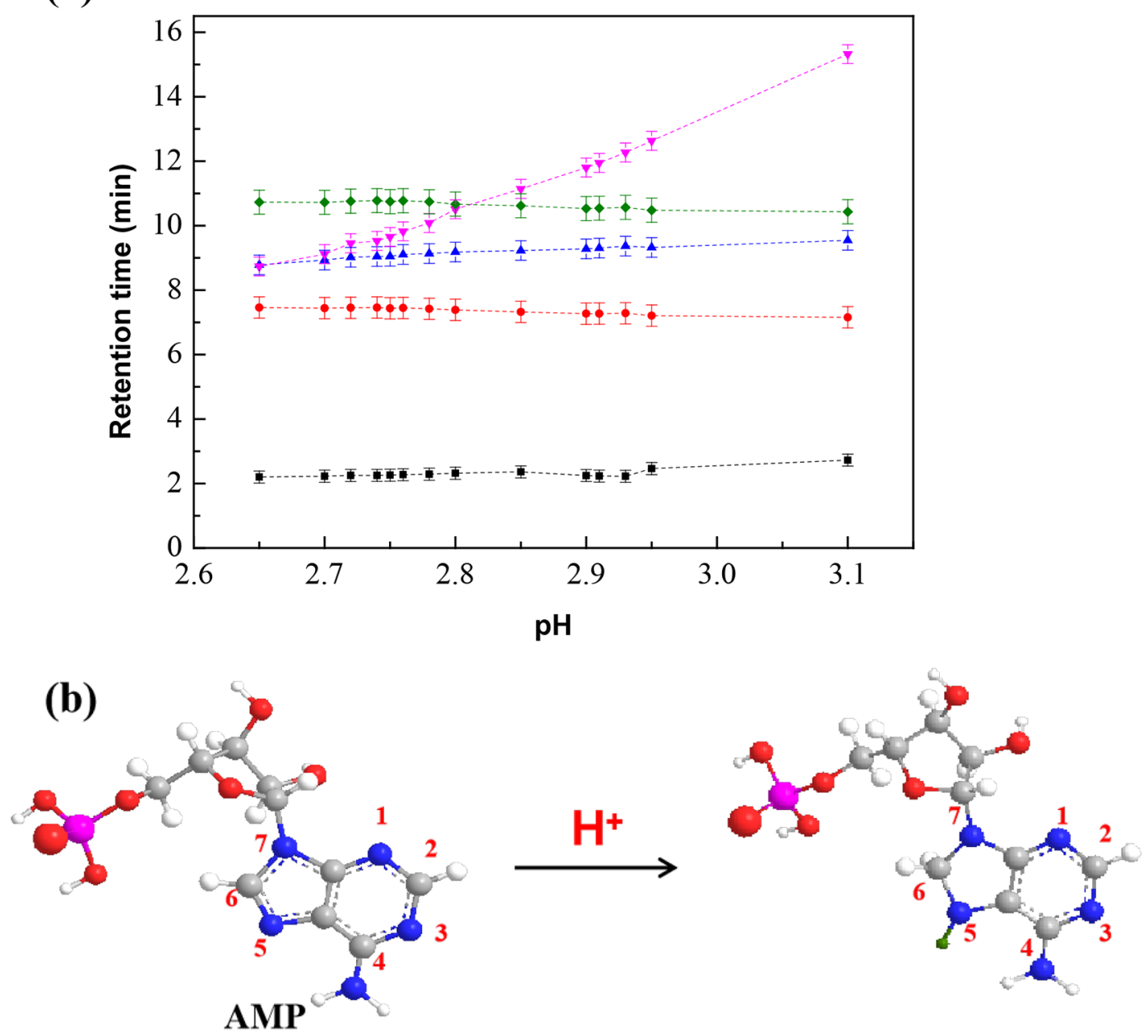

Figure 2. Effects of the HPLC mobile phase $\mathrm{pH}$ on (a) retention time of 5 nucleotides, and (b) the potential change of chemical structure of AMP. The range of retention time at different temperatures represent the width of the nucleotides' chromatographic peaks. Symbols are represented as follows: $(\boldsymbol{\square})$ cytidine $5^{\prime}$-monophosphate, $(\bullet)$ uridine monophosphate, $(\mathbf{\Delta})$ guanine monophosphate, $(\mathbf{\nabla})$ AMP, and $(\bullet)$ inosine monophosphate. The numbers on the rings are arranged according to the International Union of Pure and Applied Chemistry (IUPAC) nomenclature. 
(a)
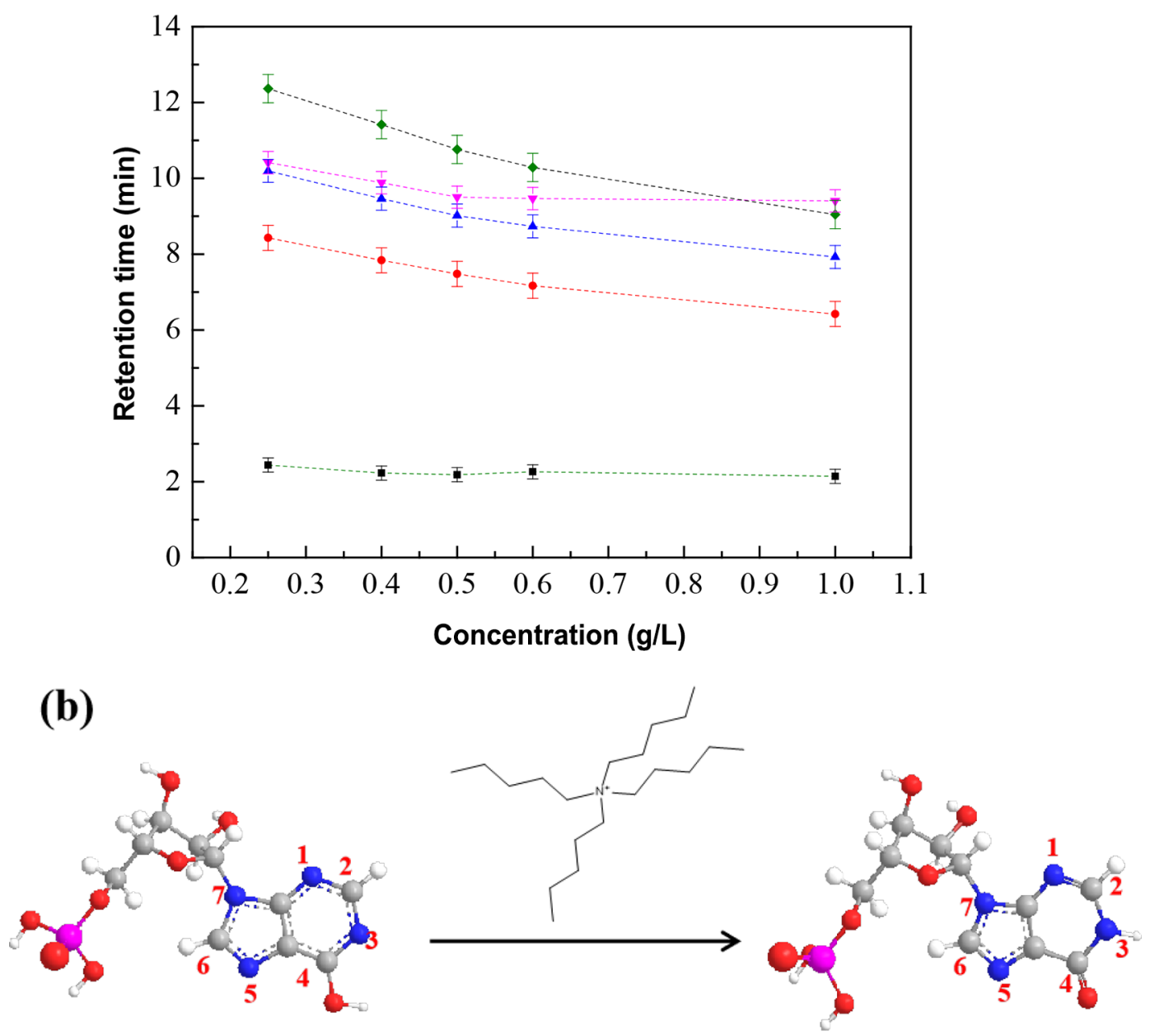

IMP

Figure 3. Effects of ion-pair reagent concentration on (a) retention time of 5 nucleotides, and (b) the potential change of chemical structure of inosine monophosphate (IMP). The range of retention time at different temperatures represent the width of the nucleotides' chromatographic peaks. Symbols are represented as follows: $(\mathbf{\square})$ cytidine 5 '-monophosphate, $(\boldsymbol{\bullet})$ uridine monophosphate, $(\mathbf{\Delta})$ guanine monophosphate, $(\boldsymbol{\nabla})$ AMP, and $(\downarrow)$ IMP. The numbers on the rings are arranged according to the International Union of Pure and Applied Chemistry (IUPAC) nomenclature.

trogen atoms (3), and the original stable structure with conjugated $\pi$ bonds on 6-membered ring was destroyed. The polarity of IMP increased, and its retention time in $\mathrm{C}_{18}$ chromatographic column shortened; as a result, the retention time curve of AMP had crossed with those of IMP and GMP.

\section{Validation of Method.}

Linearity Range and LOD Standard working solutions were prepared and diluted to $0.5,2.0,5.0$, 10.0, 20.0, 25.0, and $50.0 \mu \mathrm{g} / \mathrm{mL}$ for calibration curves. Using the concentration and the corresponding peak area as abscissa and ordinate to conduct the linear regression calculation, the calibration equations and determination coefficients were obtained. Calibration curves possess excellent linearity $\left(\mathrm{R}^{2}>0.99996\right)$ over the established concentration points, demonstrating good correlations between the relative peak areas and the nucleotide content in the samples (Table 1). According to the mathematical Eq. 1 and 2 mentioned above, the instrumental detection limit and the quantification limit of each analyte were similar. To simplify the experiments and calculations, the maximum result among the analytes was selected as the instrumental detection limit and quantification limit of the method. The method detection limit and quantification limit were multiplied by the dilution ratio of the sample in 
Table 1. Standard curve equation, coefficient of determination, and linear range of nucleotides

\begin{tabular}{llcc}
\hline & \multicolumn{3}{c}{ Linear regression data } \\
\cline { 2 - 4 } & Regressive equation & $\begin{array}{c}\text { Test range } \\
(\mathrm{mg} / \mathrm{L})\end{array}$ & $\mathrm{R}^{2}$ \\
\hline Analyte $^{1}$ & $\mathrm{y}=2,288.61 \mathrm{x}+29.3391$ & $0.50-50.00$ & 0.99998 \\
CMP & $\mathrm{y}=5,091.27 \mathrm{x}-138.014$ & $0.50-50.00$ & 0.99999 \\
UMP & $\mathrm{y}=7,268.32 \mathrm{x}-86.6644$ & $0.50-50.00$ & 0.99998 \\
GMP & $\mathrm{y}=7,556.60 \mathrm{x}-62.6445$ & $0.50-50.00$ & 0.99998 \\
AMP & $\mathrm{y}=5,461.72 \mathrm{x}+324.035$ & $0.50-50.00$ & 0.99996 \\
IMP &
\end{tabular}

$\overline{{ }^{1} \mathrm{CMP}}=$ cytidine $5^{\prime}$-monophosphate; UMP = uridine monophosphate; $\mathrm{GMP}=$ guanine monophosphate; IMP = inosine monophosphate.

the pretreatment, and the results were $3 \mathrm{mg} / \mathrm{kg}$ and $10 \mathrm{mg} / \mathrm{kg}$, respectively. Meanwhile, the linear range of the method was 10 to $1,000 \mathrm{mg} / \mathrm{kg}$. The detection was appropriate because the limitations set by different countries were within the range.

Specificity and Precision In the spike-and-recovery experiments, samples were spiked with the analyte at 3 different concentrations of 10.0, 20.0, and 60.0 $\mathrm{mg} / \mathrm{kg}$. Six replicates of each concentration level were studied. The chromatographic peaks of the nucleotides were symmetrical with the trailing factors ranging from 0.96 to 1.02 (Figure 4). Compared with the unsatisfied separation of the CMP peak in the original method, the resolution in the optimized method was 0.98 , which was a better separation effect. Through the HPLC-UV test, it was found that the nucleotide spike-and-recovery rate was in the range of 80.0 to $110.0 \%$, whereas the relative standard deviation varied from 0.5 to $3.5 \%(\mathrm{n}=6$;

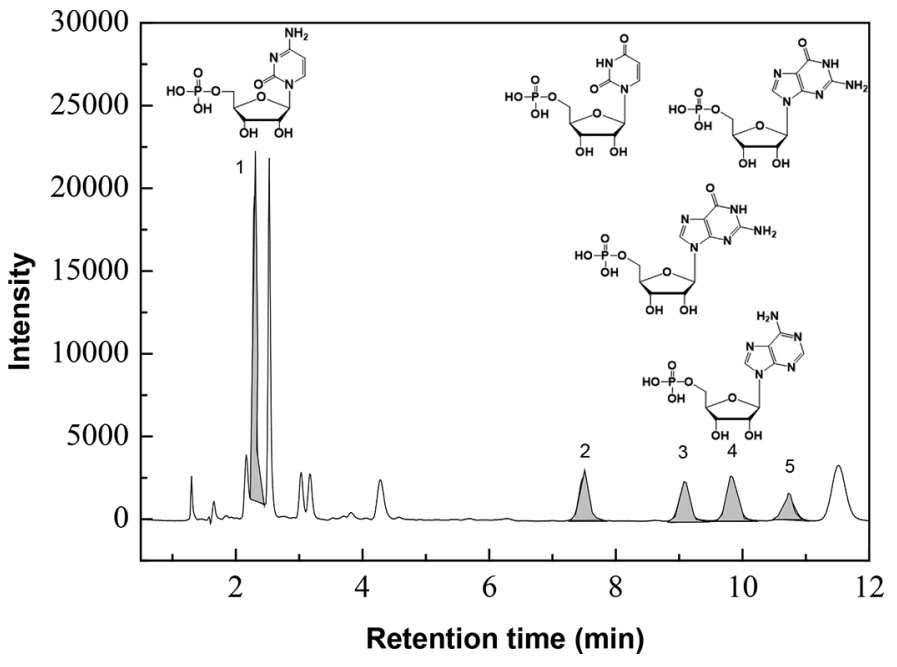

Figure 4. Typical chromatograms of cytidine 5'-monophosphate (peak 1), uridine monophosphate (peak 2), guanine monophosphate (peak 3), AMP (peak 4), and inosine monophosphate (peak 5) in formula milk powder.

Table 2). Both of the values were within the acceptable limits, as suggested by the AOAC (Sullivan, 2012); therefore, it could meet the requirement of analysis.

Authentic Samples To access the applicability and robustness of the proposed method, 17 samples of infant formula from different countries were analyzed by this newly developed method. The results reported in Table 3 show that 3 of 17 milk powder samples were not qualified. The total contents of nucleotides in one sample exceeded the maximum limit set by Chinese

Table 2. Recovery rates of matrices of nucleotides added at different levels in milk powder

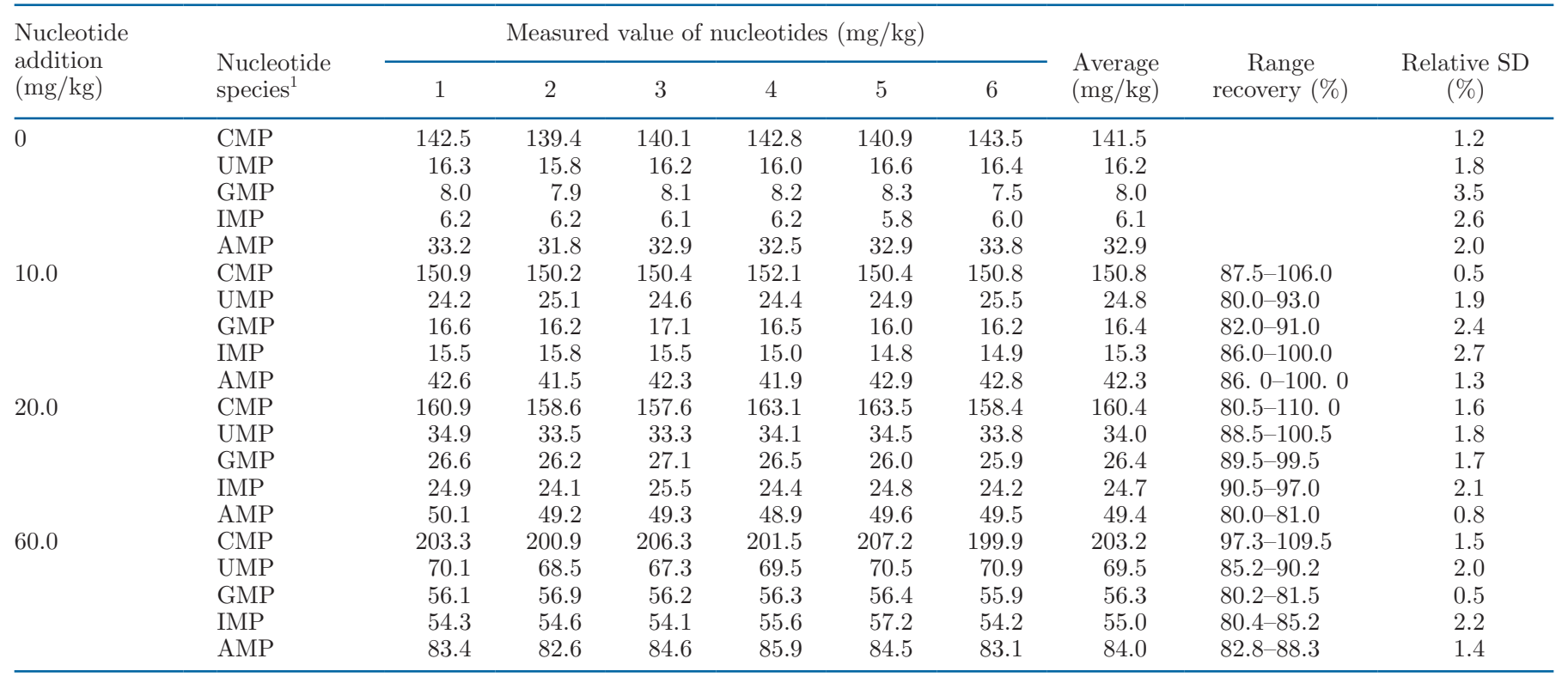

${ }^{1} \mathrm{CMP}=$ cytidine $5^{\prime}$-monophosphate; UMP $=$ uridine monophosphate; GMP = guanine monophosphate; IMP = inosine monophosphate. 
Table 3. Results of detecting the total contents of 5 nucleotides in unqualified infant formula sold on the market

\begin{tabular}{|c|c|c|c|c|c|c|c|}
\hline Country of origin & Brand & $\underset{(\mathrm{mg} / 100 \mathrm{~g})}{\operatorname{Maximum} \operatorname{limit}^{1}}$ & $\begin{array}{l}\text { Detection value } \\
\quad(\mathrm{mg} / 100 \mathrm{~g})\end{array}$ & $\begin{array}{l}\text { Relative SD } \\
(\mathrm{n}=3 ; \%)\end{array}$ & $\begin{array}{l}\text { Exceed } \\
\text { or not }^{2}\end{array}$ & $\begin{array}{l}\text { Identity value }^{3} \\
(\mathrm{mg} / 100 \mathrm{~g})\end{array}$ & $\begin{array}{l}\text { False } \\
\text { or true }\end{array}$ \\
\hline New Zealand & $\mathrm{A}$ & 58.00 & 62.96 & 2.3 & Exceed & 30.00 & True \\
\hline China & B & 58.00 & 13.24 & 1.5 & Not & 20.00 & False \\
\hline
\end{tabular}

\footnotetext{
${ }^{1}$ Maximum limit: the total contents of nucleotides set by Chinese government.

${ }^{2}$ Exceed or not: the detection value exceeds the maximum limit or not.

${ }^{3}$ Identity value: the content of added nucleotides identified on the product label.

${ }^{4}$ False or true: when the detection value $<70 \%$ of the identity value, the label information is false; when the detection value $\geq$ the identity value, the label information is true.
}

government (Ministry of Health of the People's Republic of China, 2012), and 2 of 17 samples had much lower content than the identity value. It is qualified that the detection value is higher than the label value because there is a certain number of nucleotides in milk powder itself. Therefore, it can be considered that the content of nucleotides in most infant formula milk powders in China's domestic market is qualified. At present, the market volume of the infant formula milk powder reached 177.3 billion yuan (US\$27.89 billion) in 2019 with an annual growth of $12.4 \%$, and will keep growing due to the positive fertility policy in China (Hua Jing Industrial Research Institute, 2020). Faced with a large demand for detection, the developed method cut the cost with a cheaper HPLC-UV detector compared with the HPLC-MS (Mateos-Vivas et al., 2016). What is more, the chosen type of column has a long service life (100-testing-time by conservative estimate), whereas the other types used in reports (Ministry of Health of the People's Republic of China, 2012; Mateos-Vivas et al., 2016) had an unstable performance after 20 samples in the pre-experiment. Hence, this method has a strong practicality.

\section{CONCLUSIONS}

The study revealed that nucleotides are susceptible to column temperature, $\mathrm{pH}$, and concentration of ion reagent THS in chromatographic separation. The optimal conditions were concluded. Their structures changed under different chromatographic conditions, resulting in the failure of separation of AMP and IMP or GMP. The interference of the separation was due to the different nitrogenous base composition between the AMP and the other 4 nucleotides. In this method, the linear range of single nucleotide could be detected from 10 to $1,000 \mathrm{mg} / \mathrm{kg}$, covering the requirement of conventional nucleotide addition (national standard). The recovery of standard addition was 80.0 to $110.0 \%$, and the relative standard deviation ranged from 0.5 to $3.5 \%(\mathrm{n}=6)$. This method was applied to analyze com- mercial infant formula samples and achieved satisfactory results. The variation of 5 nucleotides summarized in this study under different conditions will provide the direction and theoretical basis for optimizing the separation, preparation and detection of nucleotides.

\section{ACKNOWLEDGMENTS}

This work was financially supported by Science and Technology Planning Project in Key Areas of Guangdong Province, China (no. 2019B020211001), Guangzhou Planned Program in Science and Technology, China (no. 201803020044), National Key Research and Development Program of China, China (no. 2017YFC1601705), and Guangdong Provincial Department of Agriculture, China (no. 2019KJ130). Support was also provided by the social welfare and basic research projects in Zhongshan city, China (no. 2020B2008). Yuanjia Chen conducted the experiment, wrote the original draft, and provided validation; Lin Luo and Xiaoqun Wei provided supervision; Peiyan Feng contributed to the data curation; Hongtao Lei provided project administration; Xiaoqun Wei and Baojun $\mathrm{Xu}$ wrote the review and contributed to editing and conceptualization. All authors have given approval to the final version of the manuscript. The authors have not stated any conflicts of interest.

\section{REFERENCES}

Buszewski, B., and S. Noga. 2012. Hydrophilic interaction liquid chromatography (HILIC)-A powerful separation technique. Anal. Bioanal. Chem. 402:231-247. https://doi.org/10.1007/s00216-011 $-5308-5$.

Chen, W., J. Chen, X. Zhou, B. Chen, X. Xu, Z. Liu, J. Liang, and F. Wang. 2020. Determination of nucleotides in infant nutrition milk powder by high performance liquid chromatography. J. Anal. Sci. 63:851-856. https://doi.org/10.13526/j.issn.1006-6144.2020.06 .013 .

Chen, X., Z. Liu, and L. Gong. 2021. Evaluating the interplay among stationary phases/ ion-pairing reagents/sequences for liquid chromatography mass spectrometry analysis of oligonucleotides. Anal. Biochem. 625:114194. https://doi.org/10.1016/j.ab.2021.114194.

Codex Alimentarius. 2020. Standard for infant formula and formulas for special medical purposes intended for infants. CXS 
72-1981. Accessed Jul. 21, 2021. http://www.fao.org/fao-who -codexalimentarius/codex-texts/list-standards/en/.

Cohen, S., L. P. Jordheim, M. Megherbi, C. Dumontet, and J. Guitton. 2010. Liquid chromatographic methods for the determination of endogenous nucleotides and nucleotide analogs used in cancer therapy: A review. J. Chromatogr. B Analyt. Technol. Biomed. Life Sci. 878:1912-1928. https://doi.org/10.1016/j.jchromb.2010 .05 .016 .

Doo, E. H., C. Chassard, C. Schwab, and C. Lacroix. 2017. Effect of dietary nucleosides and yeast extracts on composition and metabolic activity of infant gut microbiota in PolyFermS colonic fermentation models. FEMS Microbiol. Ecol. 93. https://doi.org/10 $.1093 /$ femsec/fix088.

European Union. 2016. Commission Delegated Regulation (EU) 2016/127 of 25 September 2015. Accessed Jul. 21, 2021. https: / / eur-lex.europa.eu/legal-content/EN/TXT/?uri=CELEX \%3A32016R0127\&qid=1626838806208/.

Food Standards Australia New Zealand. 2019. Standard 2.9.1 Infant formula products. Accessed Jul. 31, 2021. https://www.legislation .gov.au/Details/F2021C00323/.

Garwolińska, D., J. Namiesnik, A. Kot-Wasik, and W. Hewelt-Belka. 2018. Chemistry of human breast milk-A comprehensive review of the composition and role of milk metabolites in child development. J. Agric. Food Chem. 66:11881-11896. https://doi.org/10.1021/ acs.jafc.8b04031.

Gil, A. 2002. Modulation of the immune response mediated by dietary nucleotides. Eur. J. Clin. Nutr. 56(S3):S1-S4. https://doi.org/10 $.1038 /$ sj.ejcn.1601475.

Gill, B. D., and H. E. Indyk. 2007. Development and application of a liquid chromatographic method for analysis of nucleotides and nucleosides in milk and infant formulas. Int. Dairy J. 17:596-605. https://doi.org/10.1016/j.idairyj.2006.08.001.

Gill, B. D., H. E. Indyk, and M. Manley-Harris. 2013. Analysis of nucleosides and nucleotides in infant formula by liquid chromatography-tandem mass spectrometry. Anal. Bioanal. Chem. 405:53115319. https://doi.org/10.1007/s00216-013-6935-9.

Hua Jing Industrial Research Institute. 2020. Infant formula industry development status analysis, policy to promote industry integration. Accessed Nov. 23, 2021. https://www.huaon.com/channel/ trend/654066.html

Inoue, K., R. Obara, T. Hino, and H. Oka. 2010. Development and application of an HILIC-MS/MS method for the quantitation of nucleotides in infant formula. J. Agric. Food Chem. 58:9918-9924. https://doi.org/10.1021/jf102023p.

Johnsen, E., S. R. Wilson, I. Odsbu, A. Krapp, H. Malerod, K. Skarstad, and E. Lundanes. 2011. Hydrophilic interaction chromatography of nucleoside triphosphates with temperature as a separation parameter. J. Chromatogr. A 1218:5981-5986. https://doi .org/10.1016/j.chroma.2011.01.066.

Ma, S., X. Wang, K. Xia, N. Qiu, and J. Shi. 2019. Determination of five nucleotides in infant formula milk powder by ultra performance liquid chromatography. Chin. Dairy Ind. 47:46-49. https://kns .cnki.net/kcms/detail/detail.aspx?FileName=RPGY201905011\& DbName=CJFQ2019.

Mateos-Vivas, M., E. Rodriguez-Gonzalo, J. Dominguez-Alvarez, D. Garcia-Gomez, and R. Carabias-Martinez. 2016. Determination of nucleosides and nucleotides in baby foods by hydrophilic interaction chromatography coupled to tandem mass spectrometry in the presence of hydrophilic ion-pairing reagents. Food Chem. 211:827835. https://doi.org/10.1016/j.foodchem.2016.05.091.

Mateos-Vivas, M., E. Rodriguez-Gonzalo, D. Garcia-Gomez, and R. Carabias-Martinez. 2015. Hydrophilic interaction chromatography coupled to tandem mass spectrometry in the presence of hydrophilic ion-pairing reagents for the separation of nucleosides and nucleotide mono-, di- and triphosphates. J. Chromatogr. A 1414:129-137. https://doi.org/10.1016/j.chroma.2015.08.040.

Ministry of Health of the People's Republic of China. 2012. National food safety standard-Food nutrition fortifier standard. GB 148802012 .
Qiao, J., C. Liang, Z. Cao, and H. Lian. 2018. Retention behavior of oligonucleotides under system containing mixed ion-pair reagents by IP-RPLC. Chem. J. Chin. Univ. 39:1893-1903. https://doi.org/ 10.7503 / jjcu20180262.

Sánchez, C. L., J. Cubero, J. Sanchez, B. Chanclon, M. Rivero, A. B. Rodriguez, and C. Barriga. 2009. The possible role of human milk nucleotides as sleep inducers. Nutr. Neurosci. 12:2-8. https://doi .org/10.1179/147683009X388922.

Seifar, R. M., C. Ras, J. C. van Dam, W. M. van Gulik, J. J. Heijnen, and W. A. van Winden. 2009. Simultaneous quantification of free nucleotides in complex biological samples using ion pair reversed phase liquid chromatography isotope dilution tandem mass spectrometry. Anal. Biochem. 388:213-219. https://doi.org/10.1016/j ab.2009.02.025

Sheina, G. G., E. D. Radchenko, and L. P. Blagoi. 1985. The keto-enol tautomerism of guanline. Dokl. Akad. Nauk SSSR 282:1497-1501.

Siahanidou, T., H. Mandyla, I. Papassotiriou, and D. Anagnostakis. 2004. Serum lipids in preterm infants fed a formula supplemented with nucleotides. J. Pediatr. Gastroenterol. Nutr. 38:56-60. https: //doi.org/10.1097/00005176-200401000-00013.

Singhal, A., K. Kennedy, J. Lanigan, H. Clough, W. Jenkins, A. EliasJones, T. Stephenson, P. Dudek, and A. Lucas. 2010. Dietary nucleotides and early growth in formula-fed infants: A randomized controlled trial. Pediatrics 126:e946-e953. https://doi.org/10 .1542 /peds.2009-2609.

Studzińska, S., and B. Buszewski. 2013. Effect of mobile phase pH on the retention of nucleotides on different stationary phases for high-performance liquid chromatography. Anal. Bioanal. Chem. 405:1663-1672. https://doi.org/10.1007/s00216-012-6590-6.

Sullivan, D. 2012. Infant formula and adult/pediatric nutritional methods approved First Action using the AOAC voluntary consensus standards process. J. AOAC Int. 95:287-290. https://doi .org/10.5740/jaoacint.Sullivan_Intro.

Viñas, P., N. Campillo, G. F. Melgarejo, M. I. Vasallo, I. López-García, and M. Hernández-Córdoba. 2010. Ion-pair high-performance liquid chromatography with diode array detection coupled to dual electrospray atmospheric pressure chemical ionization time-offlight mass spectrometry for the determination of nucleotides in baby foods. J. Chromatogr. A 1217:5197-5203. https://doi.org/10 .1016/j.chroma.2010.06.014.

Wang, L., S. Mu, X. Xu, Z. Shi, and L. Shen. 2019. Effects of dietary nucleotide supplementation on growth in infants: A meta-analysis of randomized controlled trials. Eur. J. Nutr. 58:1213-1221. https: //doi.org/10.1007/s00394-018-1640-2.

Yang, F. Q., D. Li, K. Feng, D. Hu, and S. Li. 2010. Determination of nucleotides, nucleosides and their transformation products in Cordyceps by ion-pairing reversed-phase liquid chromatographymass spectrometry. J. Chromatogr. A 1217:5501-5510. https://doi .org/10.1016/j.chroma.2010.06.062.

Yau, K. I., C. B. Huang, W. Chen, S. J. Chen, Y. H. Chou, F. Y. Huang, K. E. Kua, N. Chen, M. McCue, F. A. Alarcon, R. L. Tressler, G. M. Comer, G. Baggs, R. J. Merritt, and M. L. Masor. 2003. Effect of nucleotides on diarrhea and immune responses in healthy term infants in Taiwan. J. Pediatr. Gastroenterol. Nutr. 36:37-43. https://doi.org/10.1097/00005176-200301000-00009.

Zhang, T., M. Zeng, Y. Jin, and L. Liu. 2014. Determination of nucleosides and nucleotides in breast milk and infant formula by reversed phase liquid chromatography-tandem mass spectrometry. Chin. J. Anal. Chem. 42:585-591.

Zhu, B., H. Wei, Q. Wang, F. Li, J. Dai, C. Yan, and Y. Cheng. 2018. A simultaneously quantitative method to profiling twenty endogenous nucleosides and nucleotides in cancer cells using UHPLCMS/MS. Talanta 179:615-623. https://doi.org/10.1016/j.talanta .2017.11.054. 